\section{Providing appropriate genetic information to healthy multi-ethnic carriers of hemoglobinopathy in The Netherlands}

Piero C. Giordano, ${ }^{1}$ Natasha B.D. Binda, ${ }^{1}$ Antonio Amato, ${ }^{2}$ Engbert Bakker, Cornelis L. Harteveld'

'Human and Clinical Genetics Department, Hemoglobinopathies Laboratory, Leiden University Medical Center, The Netherlands; ${ }^{2}$ Associazione Nazionale Microcitemie Italia (ANMI ONLUS), Centro Studi Microcitemie di Roma (CSMR), Rome, Italy

\section{Abstract}

The aims of this study are: i) to enquire whether informing healthy hemoglobinopathy carriers about their condition is a welcome initiative in The Netherlands; ii) to study whether using information letters and thorough explanation is associated with presence or absence of undesired feelings or emotions. We have approached 100 multi-ethnic carriers previously diagnosed in our lab. All subjects had previously received our information letter through their physician who was supposed to have provided an explanation of the letter if required. We have enquired whether the subjects had experienced negative or positive emotions after receiving our diagnosis and explanation and to which degree, if they were sufficiently informed and satisfied and if they would have considered prevention in case of risk. The rate negative versus positive feelings was calculated using a numerical distribution. We have registered negative feelings in a rate that was directly proportional to the lack of information. While the number of registered negative feelings in well-informed carriers was very low it was more present in badly informed. Nevertheless, all participants found carrier information a welcome initiative and over $80 \%$ of them declared to be in favor of prenatal diagnosis in case of risk. Carrier information is essential for an informed reproductive choice and is welcome in a multi-ethnic society. Unfortunately, information is not always consequently provided and should therefore be imbedded in the ongoing national screening for Rhesus and infectious diseases available to all women in early pregnancy.

\section{Introduction}

At the end of the 90s a large cohort $(n=1000)$ of $\beta$-thalassemia carriers diagnosed at Leiden University reference laboratory was asked to cooperate in a molecular screening project. ${ }^{1}$ Much to our surprise, we discovered that over $80 \%$ of the participants had no idea of the genetic implications of the diagnosis and did not recall to have been informed by a specialist or by their general practitioner (GP). What the patients in general recalled was to have been told something like it is a hereditary condition but it is not severe and the patient had to learn living with it. Virtually none of the patients was advised to have family or partner analysis and some of them even continued to get iron prescriptions from their GP.

At that time most diagnostic requests were sent by hematologists because of persistent microcytic anemia not responding to the iron therapy prescribed by the GP. Since we did not know whether the information failure was at the specialists or at the GP's level, we started sending information to both, including an explanation on genetic risk and partner analysis whenever we had a carrier diagnosed in our lab. At some point we got an objection from a specialist. His point of view was that (eventually) informing the GP on the genetic risk of the patients was his responsibility and not ours. Although we fully agreed with that, we were able to show that we had taken our initiative because so many patients diagnosed in our lab had not been informed. The objection was dropped and we could continue providing information letters. Though, to act in collaboration with doctors, we decided to modify the procedure by addressing the letter to the patient and by sending it in an open envelop to the involved doctors, asking to explain the content to the patient according to their own judgment. In this way we could provide the eventually unaware doctors with the correct information they needed to give case by case, but leaving the responsibility to inform the patient to the best judgment of the treating doctor. We have been using these letters for nearly 20 years adding illustrated multilingual flyers to facilitate multi-ethnic communication and in the same period we started proposing all labs in the Netherlands to ad essential genetic information to all positive hemoglobinopathy results like we were doing. In the end, a working party of the national laboratory hematology association enquired on the quality of specific laboratory diagnostics countrywide and advised the use of a basic diagnostic protocol for hemoglobinopathies. The protocol included the addition of a short genetic information advising parents, partner or family-analysis in case of a carrier diagnosed in childhood, young or elderly age respectively. ${ }^{2}$ To date, the major-
Correspondence: Piero C. Giordano, Human and Clinical Genetics Department, Hemoglobinopathies Laboratory, Leiden University Medical Center, Leiden, The Netherlands.

E-mail: p.c.giordano@lumc.nl

Key words: carrier testing, counseling, information, thalassemia, sickle cell disease.

Acknowledgements: this study has been conducted according to the Local Ethical Regulations and without conflicts of interests.

Received for publication: 10 July 2013.

Revision received: 23 Feruary 2014.

Accepted for publication: 19 March 2014.

This work is licensed under a Creative Commons Attribution 3.0 License (by-nc 3.0).

(C) Copyright P.C. Giordano et al., 2014

Licensee PAGEPress, Italy

Thalassemia Reports 2014; 4:1822

doi:10.4081/thal.2014.1822

ity of the Dutch laboratories use this brief genetic information ${ }^{3}$ and some dedicated labs use a more extended letter addressed to the patients as the one we have been using in Leiden. The discussion about providing information to healthy carriers started again in the Netherlands in 2006, when the addition of hemoglobinopathies to the national newborn screening (NBS) had to be planned. Then, questions like should we report or not carriers found during neonatal screening started to occupy ethical minds in view of the fact that: i) these carriers are minors; and ii) information to carriers might provoke undesired anxiety and according to some this would cause more damage then good. Of course it is not the newborn carrier that is informed but the parents and the argument that information could do more damage then good has been proved wrong already. ${ }^{4}$ Nevertheless, anno 2012 the discussion is still ongoing and only those $\approx 800$ carriers of hemoglobin ( $\mathrm{Hb}) \mathrm{S}$, found during NBS, are reported while all other carriers (HbC, E, D, $\beta$-thal, etc.), also associated with severe conditions when present in couples at risk, are registered but not reported in spite of parents asking for information. ${ }^{5}$ To help national public health authorities to come to a sensible decision on this issue we have decided to demonstrate once again that: i) informing carriers is a good initiative; ii) that well provided information does not produce more anxiety then benefit; iii) that information is welcome to potential couples at risk; and that iv) thanks to this information, these couples might be able to choose for prevention taking a well informed reproductive choice.

We have been studying the advantages and 
disadvantages of carrier information in two parallel studies using similar strategies and similar multiethnic population samples. The first study, recently concluded and published, has been done in a country where information and prevention have a successful history of over 40 years. ${ }^{6}$ The present study is done in The Netherlands, a country in which the process of providing prospective genetic information to multi-ethnic couples at risk seeking a healthy progeny have been ongoing with insufficient success for over 20 years. ${ }^{7,8}$ From the results of NBS we know that in The Netherlands we can expect an annual incidence of at least 60 cases severely affected with sickle cell disease (SCD), thalassemia major (TM) or intermedia caused by a broad spectrum of genotypes. Most of these are SCD and are born from the Black Surinamese, the African and the Asian immigrants while thalassemia patient are born from many ethnic groups from Mediterranean to Asian, from Middle East, Iran, Iraq and from mixed couples including some Dutch case. From these figures we know that about 250 couples at risk are getting a child each year with $25 \%$ chance of being affected. With over 100 clinical laboratories, 8 genetic centers in the country and all information efforts mentioned above, one could expect a substantial number of these couples to be diagnosed prospectively and counseled in time for an informed reproductive choice. Conversely, and in spite of the very liberal abortion policy in the country, the number of prenatal diagnoses (PD) has remained constantly low, between 10-15 a year all through 2007-2012. In spite of 6 years NBS and the initiatives mentioned above, a peculiar reluctance to properly inform carriers still persist in The Netherlands. A recent study ${ }^{9}$ has shown that potential couples at risk who had a carrier baby identified during NBS, and who should have been informed by a GP are lost in the process. Similarly, obligate couples at risk who had an affected child are mainly counseled by pediatricians who are more focused on treatment rather than retrospective primary prevention. In the end post NBS counseling of these couples in genetic centers are sporadic while another study has shown that parents who had an affected child and had to face the severity of the disease through the years would have chosen for prevention if they would have been counseled properly and in due time. ${ }^{10}$

Due to lack of information and prevention, the number of patients in all age categories that are treated in Holland is growing by 60 new cases a year and is estimated to be between 1500-2000 suffering patients and families with no hope to be cured and with very high costs of treatment for public health.

All this brings us once again to the aim or our study, which is to underline that information to diagnosed carriers, is the first pillar of prevention and to show that well provided information is welcome to carriers, does not induce negative feelings and is urgently needed in The Netherlands and in other multi-ethnic immigration countries.

\section{Materials and Methods}

We have selected a large number of carriers that were supposed to have received information as it was asked in our letters previously sent to their doctors. Our information letters contains reassuring elements and information regarding the specific carrier status, the importance of partner and or family analysis and the possibilities of prevention in case of risk. Phone numbers and addresses for additional information are included and, as mentioned above, the letters are provided with illustrated multilingual information leaflets.

General practitioners were phoned explaining our intentions and asking permission to approach their patient. Then patients were phoned explaining our intention and asking for their collaboration. This went on until we had a cohort of 100 individuals that could be interviewed in a private surrounding by a trained medical student doing her master thesis on this social medicine issue. We have registered data like name, age, gender, ethnic origin and education level. Personal data were rigorously codified. We have asked a number of questions to establish if negative or positive sensations were present at different levels. At level 1, when first receiving the diagnostic results, with or without a first explanation given by the doctor and at level 2 , after a second explanation given during our enquiry.

Because positive or negative sensations may include many factors we have measured presence or absence of a scale of feelings: ashamed/not ashamed; guilty/not guilty; ill/healthy; weak/strong; afraid/not afraid; angry/not angry; unsatisfied/satisfied; sad/not sad; surprised/not surprised and feeling different or normal as a first sign of possible stigmatization. To get measurable levels of both negative and positive sensations we have used a numeric scale from 1 to 7 with level 4 being a neutral value between negative and positive, with 1,2 , and 3 considered strong, medium and slightly negative feeling, while 5, 6 and 7 have been considered increasingly positive feelings. By adding these numeric data we have been able to produce a scale of negative versus positive feelings, which has been expressed as a percentage. After registering these feelings at level 1 the content of the letter was again explained, and the negative and positive feelings were registered again. We have also registered whether the participants were satisfied, if they had language problems, if they were feeling discriminated, if they had been searching for more information on their own, if they would have considered informing their families, if they would have chosen for prenatal diagnosis and eventually for medical abortion in case of an affected fetus or if they would have not considered this option and for which reason. Our results are presented in plain numerical figures and percentages with supporting illustrations.

\section{Results}

\section{General data}

We have registered 100 interviews of which 9 from presumed autochthonous Dutch and 91 from a multiethnic group. The most represented were recent immigrants from Surinam $(n=28)$ and Curacao $(\mathrm{n}=14)$, mostly healthy carriers of sickle cell disease, while Moroccans, Turks, Indonesians, Afghans, Iraqis and Iranians, etc. were mostly slightly anemic carriers of $\beta$-thalassemia. The ethnic distribution of our cohort is depicted in Figure 1. The average age of our cohort was 37.6 years (18-78). The gender ratio

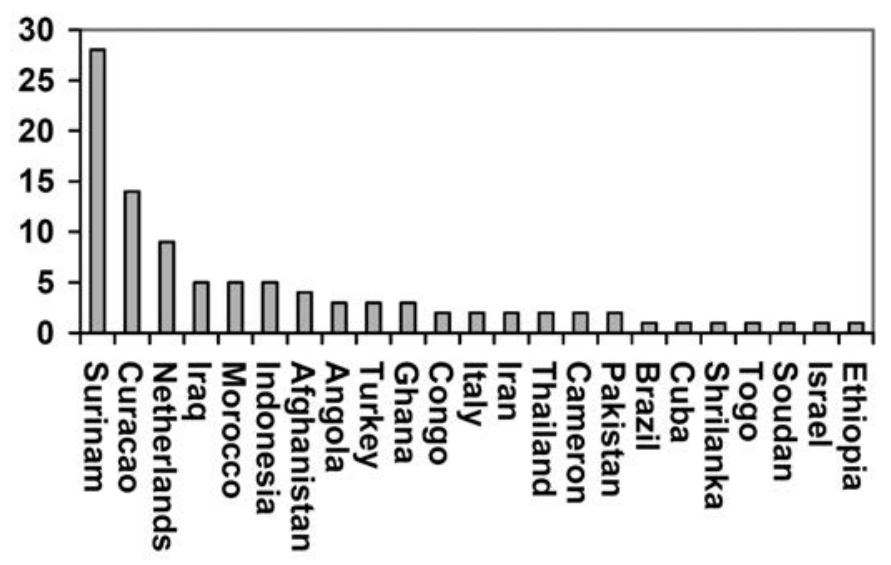

Figure 1. Ethnic distribution of the 100 individuals included in our anonymous enquiry. 
was 70 females versus 30 males. The degree of education ranged from elementary school to university (Figure 2).

\section{Information level as found at level 1}

Only $55 \%$ of the carriers received the information letter and only $41 \%$ of the carriers had the content explained by the doctor. The doctor's explanation at level 1 was considered sufficient by $36 \%$ of the respondents.

Among the $45 \%$ that did not recall to have received the letter, $35 \%$ declared not to have understood what they had been diagnosed with, while $8 \%$ did.

Only $59 \%$ of the enquired declared to have either been informed about or to be aware of the importance of partner analysis when seeking progeny or to be aware of this fact.

Lack of awareness on this specific matter was also registered among a few of those who recalled to have received a letter and an explanation (Figure 3 ). This could be probably due to a decision of the doctor not to talk about this because of the particular situation (age, no progeny or no desire of having children).

\section{Comparing negative and positive feelings at level 1 and 2}

Using the described criteria we have been able to calculate that negative feelings were present at $17.9 \%$ in the total cohort $(n=100)$ when learning the diagnostic results for the first time (level 1). The rate between negative and positive feeling is shown in Figure $4 \mathrm{~A}$ (black negative, white positive feelings).

The group that at level 1 had received no letter and no explanation ( $n=45)$ (Figure 4B) reported the highest negative feelings (23.4\%) when learning the diagnostic result for the first time. Undesired feelings are much lower $(13.3 \%)$ in the cohort that got an explanation and the letter when learning the results for the first time $(n=55)$ (Figure 4C) while the lowest level of negative feelings (6.3\%) was measured at level 2 in the total cohort $(n=100)$ after a second interactive explanation was provided during our survey (Figure 4D). In all figures negative feelings are in black while positive feelings are in white.

\section{Additional questions and answers registered at level 2}

\section{Feeling discriminated}

The question whether or not a feeling of discrimination would be present because of the disease related to ethnicity was answered by 99 subjects. Only a 30 -year old Turkish male who came to Holland recently answered yes. The same man had also the highest score of negative feelings, before and after explanation and did not answer prevention questions. The remaining 98 answered not to have felt any discrimination feeling. Not feeling discriminated as a patient or as carrier at risk for SCD or TM in the progeny, seems to be in contrast with the experiences made in the USA. ${ }^{11}$ The difference can be easily explained by the preexisting status of colored people in the USA while Dutch Blacks are not at all feeling lesser persons, rather the contrary.

\section{Understanding the message}

The question whether or not the message was clear enough was answered by 98 individuals. After the explanation eventually given by the doctor and the one provided during the enquiry a 54-year old (not worried) male from Curacao, a 26-year old Surinamese female with no opinion on PD and a 78-year old Dutch female (the oldest in our survey) still found the message unclear. A 22-year old religious Iraqi male and a 30 -year old Turkish male who had no interest in prevention did not answer. The rest of the cohort found the message welcome and clear.

\section{Language problems}

The whole cohort answered this question. Although language problems were present in 14 cases, practically all found either their own language or one they understood among the multilingual leaflets sufficient. One needed an interpreter (Berber).

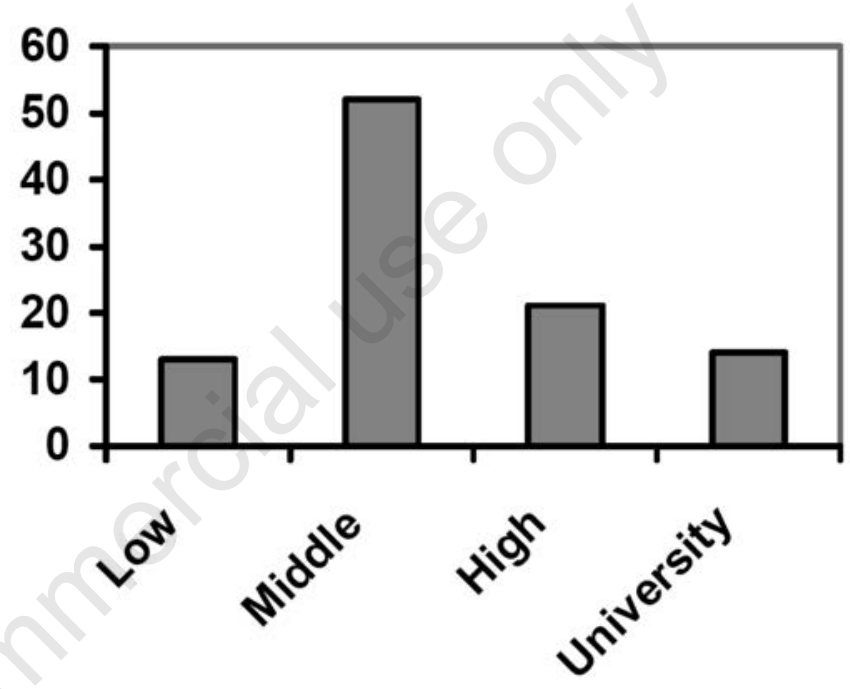

Figure 2. Education spectrum of the 100 individuals included in the anonymous enquiry.

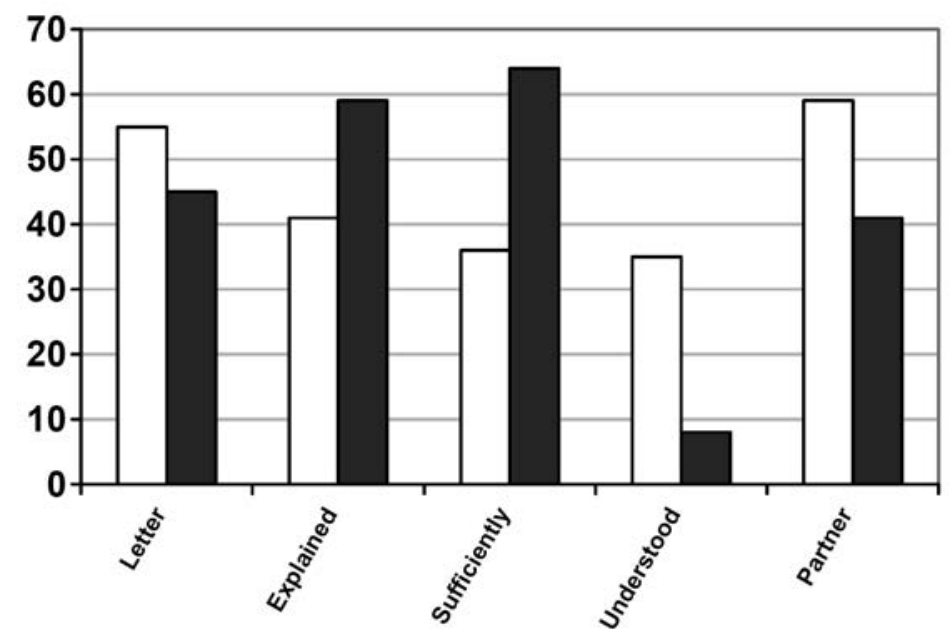

Figure 3. Information status in the 100 enquired individuals at level $\mathbf{1}$. Letter received (white)/not received (black). Letter explained (white)/not explained (black). Sufficient (white)/insufficient explanation (black). Understood (white)/not understood (black). Informed about the importance of partner analysis (white)/not informed (black). 
Second opinion

Ninety-seven answered, 13 did look for it, eventually consulting another doctor.

Independent information search

Ninety-six answered, 48 did eventually consult one of the websites mentioned in our letter such as that of our lab or of the patient's organization or consulted internet.

\section{Advantage of information}

The advantage of information was acknowledged in 99 cases. Only a 20-year old Surinamese female, although in favor of PD did not (we suspect a clerical error).

\section{Satisfaction}

All enquired were happy with the provided information but the same 20-year old Surinamese female mentioned above (probable clerical error).

\section{Family information}

Except for 6 cases that preferred to limit discussing their diagnosis to their closely related, the rest had no problems in disclosing their carrier status within their family circle.

\section{Prenatal diagnosis}

Eighty-one persons declared that they would choose for PD in case of risk for b-thalassemia major or sickle cell disease. Seven would eventually, 5 would not and 7did not answer.

\section{Aborting an affected fetus}

Medical abortion in case of a severely affected fetus was the choice of 68 respondents while 7 were not sure and 17 would keep the affected fetus to be born. Eight did not answer.

\section{Why not abortion}

Religion was mentioned by 16 of the 17 while one gave personal reasons.

\section{Asking for religious advice}

The question was answered by 86 respondents. Twenty-six would eventually ask while 60 would not. Data are summarized in Figure 5.

\section{Discussion}

\section{General considerations}

The problem of screening and informing carriers has been approached in endemic countries for many years. Some countries just applied compulsory screening either long ago (Cyprus) or more recently (Iran) with a large popular consensus because of the very high incidence. Other countries used well-organized campaigns (Sardinia), other countries
A
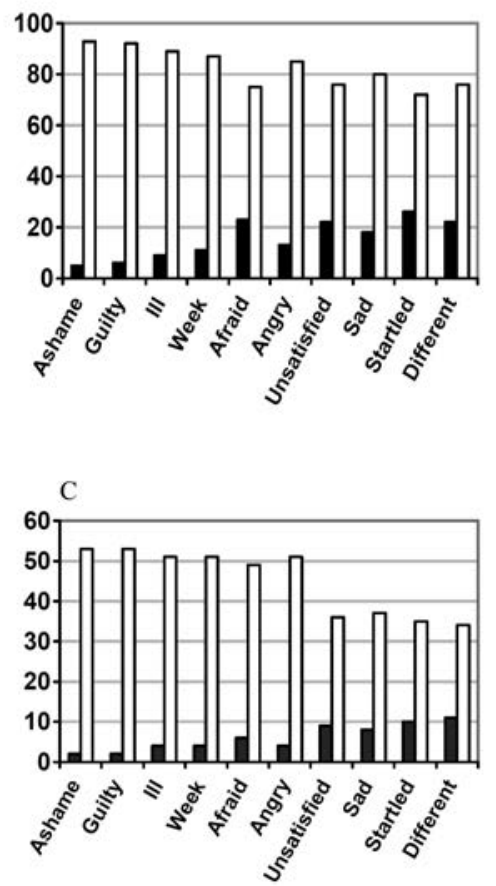

B

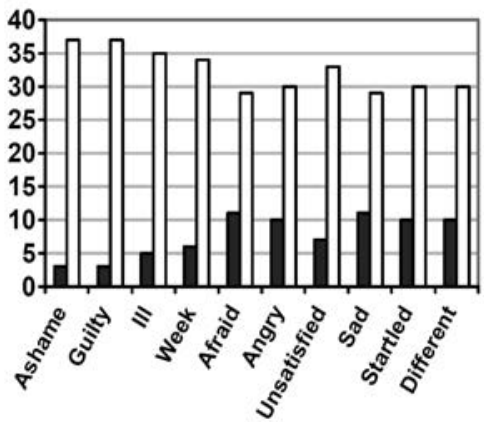

D

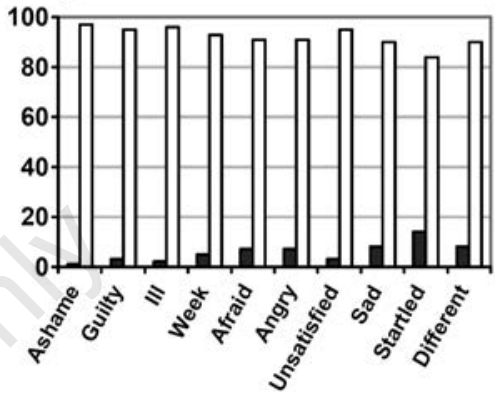

Figure 4. A) Negative (black) versus positive feelings (white) measured in the total cohort at level 1 when learning the diagnostic results for the first time with or without explanation. Negative feeling rate $17.9 \%$. B) Negative (black) versus positive feelings (white) measured at level 1 in the cohort who had no letter and no explanation when learning the diagnostic results for the first time by. Negative feeling rate $23.4 \%$. C) Negative and positive feelings measured in the cohort that had both letter and explanation at level 1. Negative feeling rate $13.3 \%$. D) Negative and positive feelings measured in the all cohort at level 2, after the explanation provided during our survey. Negative feeling rate $6.3 \%$.

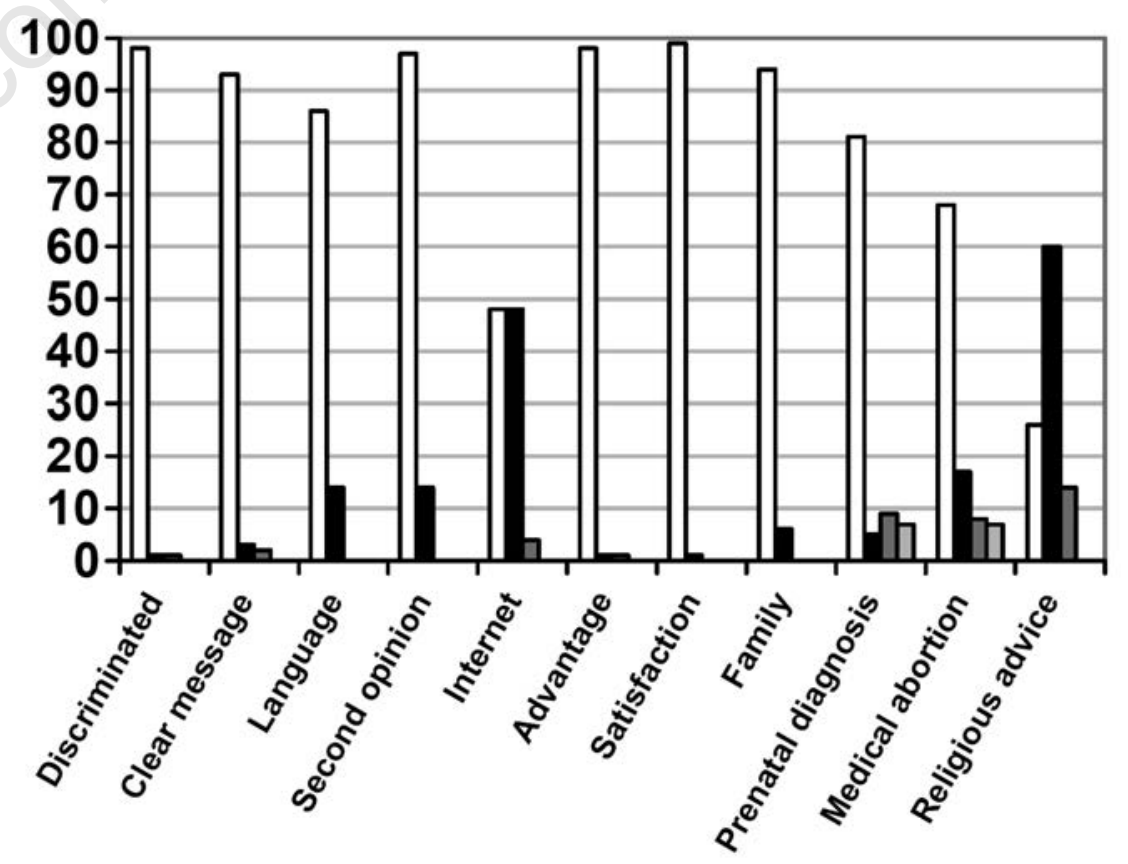

Figure 5. Additional positive (white) and negative feelings (black) registered at level 2. Missing answers are in grey may be answers (not sure) are in light grey. 
offered early pregnancy screening and provided thorough information to couples at risk keeping also patient's registry. ${ }^{12}$ Other methods are based upon informing parents after school screening. ${ }^{6}$ In spite of well-organized prevention, newcomers may escape screening and information also in endemic countries due to language problems or lack or integration. ${ }^{6}$

Among the advanced non-endemic immigration countries only the UK have implemented pre-conception screening at the national level and genetic risk information with encouraging results. ${ }^{13}$ Others countries like The Netherlands and Belgium are trying to follow this example while others countries, in spite of large populations at risk, have no organized screening or information at all, possibly still fearing the effects of ethnic discrimination that had dramatic consequences during the Second World War. ${ }^{14}$

By the turn of the century $40 \%$ of the newborn in The Netherlands was from immigrant parents and according to World Health Organization recommendations, the incidence growth of SCD and TM was largely justifying prevention measures. Nevertheless, and in spite of the many warning ${ }^{8}$ the problem remained ignored and so also the dramatic suffering of patients and parents ${ }^{15}$ and the huge costs of treatment for families and public health, recently calculated by Koren et al. around 2 million euro per life treatment per patient. ${ }^{16}$

\section{What to say during multi-ethnic counseling}

Whenever a patient receives a diagnostic result, learning that he is not ill or that the condition he has is hereditary recessive (and thus is not a disease) he feels obviously relived, in particular if he learns that the cure (iron medication) he has been endlessly prescribed for his mild chronic anemia, is not necessary anymore. One may however become upset learning about the unnecessary treatment he has got or might become frightened by the word hereditary that might be felt with some concern if we are not able to explain that hereditary does not necessarily mean a threatening severe condition yet to come. Informing carriers in multi-ethnic societies can be a totally relaxed action in one culture while it might become emotional in another if facts are not culturally well explained and well understood. If not patients may look for information on the web, confuse the non-pathological status of the carrier with the severe condition of the patient and become terribly worried. Moreover, in cultures where couples are not always traditional and responsibilities regarding the progeny are often not much felt by the male, information might involve different emotions then in cultures where the marriage of a daughter is a serious matter and often culturally arranged. Parents may then tend to dramatize when they hear about a hereditary condition because rumors of a genetic disease running in the family might result in intra-cultural social stigmatization. Moreover, talking about prevention in a society that severely condemns medical abortion legally and culturally, information may result in a rejection even if the same society has one of the highest rates of illegal abortions. ${ }^{17}$ As shown in a previous study ${ }^{10}$ the 5 Moroccans included in our enquiry wanted all to have PD but only 3 openly consider medical abortion in case of an affected fetus. It is noteworthy that privacy when talking about abortion is very important among Moroccans and that denial was in one case in the presence of a translator.

Because of these multi-cultural aspects our explanation letters contains elements that are common to all cultures and that the doctor should use to reassure the patient and explaining clearly that being a carrier is not a disease that we are all healthy carriers of recessive genetic traits that it takes two carriers to form a couple at risk that nobody can be blamed for genetic risk (but perhaps a failing public health) and that knowing to be a healthy carrier is an advantage that allows couples at risk to have healthy children.

Although in our letter things are well explained for the benefit of patients and doctors, the crucial bottlenecks at the GP level seems to the limited time available to properly explain things and the reluctance to propose partner analysis. The GP should be able to judge if the situation needs more than $10 \mathrm{~min}$. attention and if he feels comfortable enough to explain genetic risk. If not, carrier eventually seeking reassurance and prevention should be referred to a genetic center for additional explanation, partner analysis and if at risk prenatal diagnosis.

\section{Negative versus positive feelings}

Our results indicate that, regardless of the way information reaches the healthy carrier, the negative feelings are far lesser than the positive ones. Moreover, strong and medium negative feelings (type 1 and 2) were rarely present while the more positive one (type 6 or 7) were registered very often. In addition, our data indicates that information is welcome and not more burdening then any other diagnostic result excluding the presence of a disease. As expected we have found significant difference depending from the way healthy carriers have received (or not) information. As shown in Figure 4B keeping the explanation letter in the file does not help much in reducing the negative feelings and just handing it over might also be not sufficient in all cases. On the other hand, we have shown that taking time to explain things in some details results into a near absence of negative feelings (Figure 4D) and in general satisfaction (Figure 5).

\section{Regular diagnostics versus screening}

Carriers and couples at risk found during 6 years of NBS do not get our explanation letters unless they are referred to us for genotype/phenotype correlation and counseling. Moreover, we do not know what happens to our information letters when provided. In a recent study we have shown that NBS has not resulted into more counseling or lower incidence by retrospective and prospective primary prevention. ${ }^{9}$ In the present study at risk for sickle cell disease has declared to be in favor of PD and medical abortion of an affected fetus in $78 \%$ of the cases. This makes us believe that the couples at risk identified during NBS and the carriers of $\mathrm{HbS}$ may still be in need of appropriate information.

\section{Take home message}

Although well documented for efficacy and proved welcome by this and other studies, ${ }^{4,18}$ information to healthy carriers is still insufficient in The Netherlands and so far is only efficiently provided locally at the first pregnancy control. Thanks to dedicated obstetricians and to recent protocols edited by the Dutch Association for Obstetrics and Gynecology, carriers can be diagnosed and information can be successfully provided in time for partner-analysis and prevention if requested.

Several studies have proved that this strategy is applicable in The Netherland $s^{18,19}$ and implementation is ongoing in part of the country but not at the national screening level as yet. In view of all this, inclusion of hemoglobinopathies in the ongoing national Rhesus and infectious diseases screening would be the most sensible solution in The Netherlands.

\section{References}

1. Giordano PC, Harteveld CL, Heister AJ, et al. The molecular spectrum of $\beta$-thalassemia and abnormal hemoglobins in the allochthonous and autochthonous Dutch population. Community Genet 1998;1:243-51.

2. Giordano PC, Smit JW, Herruer M, et al. Dragerschapdiagnostiek en preventie van Sikkelcelziekte en Thalassemie Major; Aanbevelingen van de werkgroep hemoglobinopathieën. Ned Tijdschr Klin Chem Labgeneesk 2006;31:301-5.

3. Kaufmann J0, Smit JW, Huisman W, et al. Basic hemoglobinopathy diagnostics in Dutch laboratories; providing an informative test result. Int $\mathrm{J}$ Lab Hematol 2013;35:428-35.

4. Karetti M, Yardumian A, Karetti D, Modell B. Informing carriers of $\beta$-thalassemia: giving the good news. Genet Test 2004;8: 
109-13.

5. Giordano PC. Starting neonatal screening for haemoglobinopathies in The Netherlands. J Clin Pathol 2009;62:18-21.

6. Amato A, Lerone M, Grisanti P, et al. Providing appropriate genetic information to healthy carriers of hemoglobinopathy can be a welcome and safe initiative: the Latium example. Genet Test Mol Biomarkers 2012;16:734-8.

7. Giordano PC. Prospective and retrospective primary prevention of hemoglobinopathies in multiethnic societies. Clin Biochem 2009;42:1757-66.

8. Giordano PC, Harteveld CL. Prevention of hereditary haemoglobinopathies in The Netherlands. Ned Tijdschr Geneeskd. 2006;150:2137-41. [In Dutch].

9. et al. After the introduction into the national newborn screening program: who is receiving genetic counseling for hemoglobinopathies in the Netherlands?. Public Health Genomics 2014;17:16-22.
10. Giordano PC, Dihal AA, Harteveld CL. Estimating the attitude of immigrants toward primary prevention of the hemoglobinopathies. Prenat Diagn 2005;25:885-93.

11. Long KA, Thomas SB, Grubs RE, et al. Attitudes and beliefs of African-Americans toward genetics, genetic testing, and sickle cell disease education and awareness: $\mathrm{J}$ Genet Couns 2011;20:572-92.

12. Voskaridou E, Ladis V, Kattamis A, et al. A national registry of haemoglobinopathies in Greece: deducted demographics, trends in mortality and affected births. Ann Hematol 2012;91:1451-8.

13. Dormandy E, Reid E, Tsianakas V, et al. Offering antenatal sickle cell and thalassaemia screening in primary care: a prepost evaluation of a brief type of communication skills training. Patient Educ Couns 2012;89:129-33.

14. Eber S, Dickerhoff R. Anemia and hemoglobin diseases in patients with migration background. Dtsch Med Wochenschr
2014;139:434-40.

15. Schulpen TW, van der Lee JH, van der Most, et al. Genetic carrier screening for hemoglobinopathies in the Netherlands is not opportune. Ned Tijdschr Geneeskd 1998;142:1019-22.

16. Koren A, Profeta L, Zalman L, et al. Prevention of $\beta$ thalassemia in Northern Israel - a cost-benefit analysis. Medit $\mathrm{J}$ Haematol Infect Dis 2014. [In Press].

17. Naamane-Guessous S. Traditional methods still widely used. Plan Parent Chall 1993;1:14-6.

18. Giordano PC, Plancke A, Van Meir CA, et al. Carrier diagnostics and prevention of hemoglobinopathies in early pregnancy in The Netherlands: a pilot study. Prenat Diagn 2006;26:719-24.

19. Kaufmann JO, Demirel-Güngör G, Selles A, et al. Feasibility of nonselective testing for hemoglobinopathies in early pregnancy in The Netherlands. Prenat Diagn 2011;31: 1259-63. 